\title{
Emission Characteristics of Single Cylinder Compression Ignition (CI) Engine
}

\author{
P. RAVI KUMAR \\ Principal \& Professor, St. Ann's College of Engineering \& Technology, Chirala, \\ Prakasam, Andhra Pradesh, India \\ dr.mepravi555@gmail.com
}

\begin{abstract}
Expanding expenses of oil, fast development of industrialization and the worldwide pattern of urbanization alongside their expanding contamination by supplanting existing fuel. The point of study is to break down the performance and discharge qualities existing single barrel four stroke compression Ignition (CI) engine changed over into double fuel mode. In the current investigations the impact of compressed fossil fuel (CNG) gas acceptance on the performance on double fuel engine instead of single fuel. CNG utilised as fuel and Diesel or Biodiesel utilized as pilot fuel on double fuel mode, Karavera (Thevetia Peruviana) and Surahonne (Calophyllum inophyllum) Biodiesel ar utilised. Double fuel mode is one in all the higher methods to manage emanations from CI engines and quickly replacement existing fuel engine. Examinations is completed underneath engine centre condition, investigate the performance and outflow qualities of single chamber CI engine on double fuel mode by utilizing CNG as fuel and Diesel or biodiesels (Karavera and Surahonne) pilot fuels by unsteady injection temporal order 230 , 260 and one hundred ninety bTDC. Brake Thermal potency and Brake specific fuel utilization at double fuel technique of CNG fuel offers most popular outcomes over pure fuel engine in any respect engine hundreds. The reduction in $\mathrm{CO}$ and $\mathrm{HC}$ discharges on double fuel mode for all lots and what is more crest weight rise. By seventieth CNG fuel substitution rate.
\end{abstract}

Keywords: Compressed Natural Gas, Diesel engine, Biodiesel, Exhaust gas analyzer, Electronic gas conversion kit.

\section{Introduction}

Compressed Natural gas (CNG) Ordinary fuels like diesel and petroleum are exhausting step by step, so we need to look for an elective fuel like biodiesel, biogas, CNG, LNG, LPG, hydrogen gas, maker gas, ethanol, and so on. Among all different vaporous fuels, compacted gaseous petrol (CNG), fluid oil gas (LPG) and hydrogen are generally valuable. Double fuel process is start strategies for rationing diesel and oil, Natural gas is begin in underneath the earth peak at high weights and all the more ordinarily is connected with the oil [3].

Article history:

Received (April 23, 2019), Review Result (June 6, 2019), Accepted (September 28, 2019) 


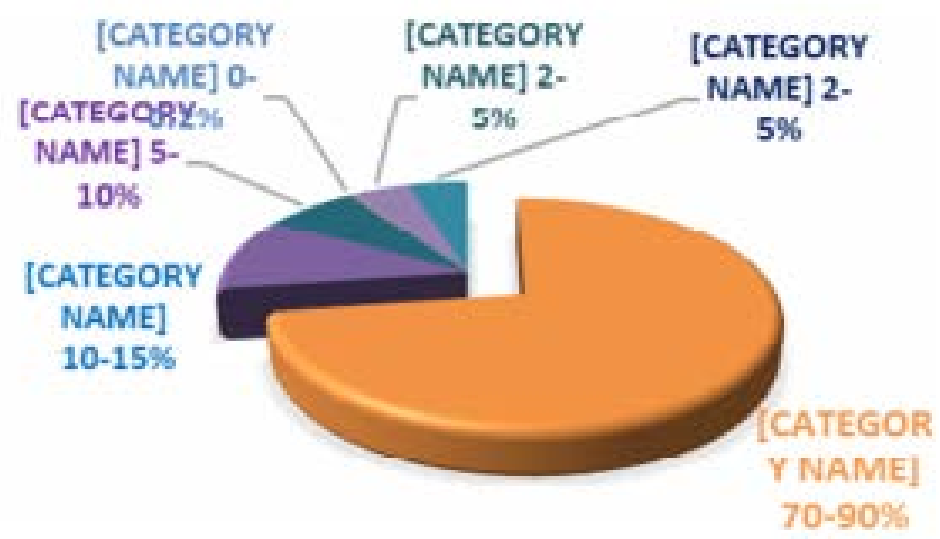

Figure 1. CNG Composition

CNG comprises of methane around 80 to 95\%, and little measures of different hydrocarbons like ethane, butane, $\mathrm{CO} 2$ and N2. Petroleum gas has a decent conceivable as supplementary fuel for IC engines. It might contain a few scums in little sums like hydrogen sulfate (H2S) and vapor molecule (H2O). It is regularly kept in cylinder to the vaporous shape at a high weight of around 200 bar for conveying. The arrangement of flammable gas separates from well to well and fluctuates from phase to phase [1].

Natural gas has been considered as a potential substitute to customary fuels in Vehicles. Use of CNG in a vehicle fuel must be impressively dynamic in the course of the most recent decade. Because of the development of lightweight high-weight stockpiling cylinder. CNG is decreased discharge and performance issues diesel engines that should be possible by utilizing double fuel mode that is diesel-CNG method of running engine [2][3]. CNG is kept up high power yield, torque and less engines outflows practically identical to the gasoline and diesel. Elective gaseous fuels are utilized by and large everywhere throughout the world. Natural gas has respectably high octane number $(\mathrm{ON})$ with low outflows than the fluid fuels. CNG is lighter than air it scatters rapidly when contrasted with different gases fuel. CNG is reasonable for engines with higher pressure proportions.

Natural gas has several advantages

Natural gas less harmful than solid and liquid fuel.

Natural gas can be easy storage and transportation.

Gas burns cleaner without smoke.

Natural gas abundant than the other vehicle fuels.

Natural gas more in industries the other fuels.

Natural gas is lighter than air so it easily dissipates when it leaked, which is used instead of LPG.

Natural gas cheaper than gasoline nearly $30 \%$ cheaper.

\section{Submission}

Currently there's a worldwide trend of improvement of criminal legislation and follow of its application. Western countries tend to maneuver removed from retaliatory, repressing criminal proceedings. the most direction of such States is restorative justice.

Restorative justice considers crime not only as a violation of the law, but primarily as a violation of the victim rights, and also that the crime was committed not so much against public order and the State, as against person. Restorative justice aims not only at punishing the 
offender and damage compensation caused to the crime victim, but also, to a certain extent, at the offender correction. It is generally recognized that the deprivation of liberty of the accused is not correct, and in many cases personality defects aggravates. Restorative justice allows to avoid such mistakes.

Mediation in criminal proceedings is regulated by law in some states of America. In North Carolina there is program for mediation in district criminal court. This program provides mediation in the court and works as an alternative to judicial investigation, but not the criminal process as a whole. In North Carolina such program is enshrined in the norms of North Carolina General Statutes, and the Supreme court adopted Supreme Court Rules to enforce these norms. In addition to the above documents, in this state there are "Rules implementing mediation in matters unfinished in district court." In accordance with these rules the court guided by inner conviction and by external factors may recommend to the parties to participate in this program.

After the case materials with the indictment document are received by the court, the district attorney (and sometimes the judge) shall inform the parties about the possibility of participation in the program of mediation. If the victim and the offender agree to participate in this program, mediation can be held directly at the courthouse. If the case involves several defendants or victims, at the court discretion, these persons can be united to participate in mediation.

The ideal result of mediation shall be mediated agreement which contains all the terms agreed upon by the parties. An obligatory condition is the written form of the agreement and signatures of both parties. In North Carolina this agreement enter into force as soon as it is signed by the parties. In Idaho, the mediated agreement was treated more seriously, and for entry into force it must be approved by the court (18.1(8)/12.1(8)).

For today, Victim-Offender Mediation program has spread beyond America and now successfully working in Canada, England and New Zealand and in other countries. Typically, the program is carried out by private non-profit or public organizations, which work closely with local court.[3]

Nowadays there are alternatives to criminal prosecution in General and alternatives to judicial stages in criminal proceedings for juvenile in State of Illinois. The state's attorney determines the list of restorative justice programmes; he controls the Register of qualified mediators. The restorative justice programme itself is performed with strict confidentiality compliance. Ideally the mediation program must result in agreement with the offender, which contains the decision on prescribed conduct of juvenile and the term within which the conditions set by the agreement are to be met. Failure to comply with the agreement by the juvenile will be the ground for criminal proceedings resumption.

In the United States restorative justice shows good results. Not accidentally the application of restorative justice programs, including in the criminal process, is recommended by a number of international legal norms, especially in resolution of criminal cases against minors. In the Russian Federation attitude to juvenile justice is ambiguous.

The restorative justice programs have already been used in the Russian criminal process without violating of the Criminal Procedure Code of the Russian Federation norms and focusing on the norms of international law.

\section{BIODIESEL}

Karavera (Thevetia Peruviana) seed oil yield is sort of 50-60\% and Surahonne (Calophyllum inophyllum) seed oil yield is concerning 55-65\% from these oils is transesterified delivering a mix of unsaturated fats group esters and glycerine. Biodiesel is alluded to because the monoalkyl-esters of long-chain-unsaturated fats got from unsaturated fat sources. Biodiesel limits 
the event of $\mathrm{CO}$ and $\mathrm{HC}$ emanations amid the burning procedure thanks to the closeness of $\mathrm{O}$. Biodiesel has high Cetane range $(\mathrm{CN})$ contrasted with the fuel. Engines square measure operating most extreme misunderstanding to half-hour of biodiesel with diesel. By utilizing CNG fuel in diesel engines are going to be minimized vitality utilization, can provides vast modification in Brake Thermal potency and what is more conservative and condition well disposed. The impact of Diesel, biodiesels mixes aboard CNG over the performance and discharge attributes of a CI engine on double fuel mode was tentatively inspected.

\section{Material and Methods}

Diesel engines (CI) run on a twin fuel mode by attaching Gas mixer at manifold of existing engine. CNG fuel utilized in twin fuel mode and Diesel and Biodiesel used as a pilot fuel.

\subsection{Fuel properties}

The properties of Diesel, CNG, Karavera (Thevetia Peruviana) and Surahonne (Calophyllum inophyllum) as shown in table 1.

Table 1. Properties of fuels

\begin{tabular}{|c|c|c|c|c|}
\hline Properties & Diesel & CNG & Karaver & Surhonn \\
\hline Density Kg/m ${ }^{3}$ & 830 & 0.6512 & 870 & 890 \\
\hline $\begin{array}{c}\text { Kinematic Consistence } \\
\left(\mathrm{mm}^{2} / \mathrm{s}\right)\end{array}$ & 3.98 & - & 4.5 & 4.925 \\
\hline Flash purpose ${ }^{0} \mathrm{C}$ & 49 & - & 164 & 169 \\
\hline Fire purpose ${ }^{0} \mathrm{C}$ & 55 & - & 174 & 178 \\
\hline Calorific worth $\mathrm{kJ} / \mathrm{Kg}$ & 42382.4 & 50020 & 40107.8 & 37874 \\
\hline
\end{tabular}

\section{Experimental test set up}

The single cylinder four stroke water cooled ICE introduced at centre. we have a tendency to run and adjusted over ICE into double fuel mode by connecting venturi gas liquidizer to consumption complicated. Four pass venturi gas liquidizer, gases fuel and admission air blends at that time stream to the cylinder through admission valve. CNG used as fuel, Diesel and Biodiesel used as a pilot fuel.

Test directed by ever-changing injection temporal arrangement with 230, 260 and one hundred ninety and therefore the engine was worked at $1500 \mathrm{rev}$, beneath naturally suctioned conditions. within the take a look at got wind of instruments were used including take a look at engine, CNG modification unit, measuring system, air box with gap meter and pressure gage, venturi gas liquidizer, CNG cylinder, weight device, speed encoder, temperature device, Electrical stacking, stack device, engine performance investigation software(engine delicate), fumes gas analyser, etc 


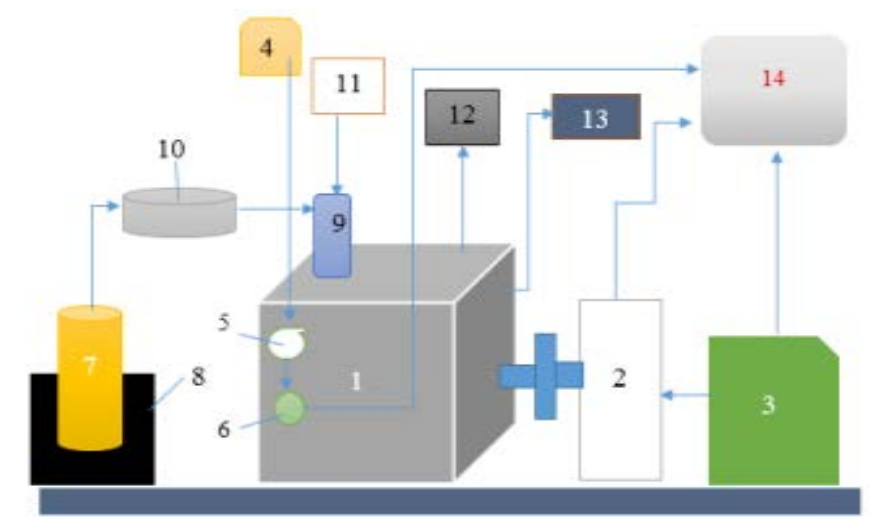

Figure 2. Schematic layout of four stroke single cylinder Diesel engine on duel fuel mode

1. Diesel Engine.

3. Electrical loading.

5. Fuel injector.

7. CNG Cylinder.

9. Gas mixer/Mixing chamber.

11. Air box.

meter.

13. Exhaust gas analyzer.
2. Alternator.

4. Fuel tank.

6. Pressure Sensor.

8. Weighing machine.

10. Electronic gas conversion Kit.

12. Exhaust temperature Measurement

14. Data stored in Computer.

Table 2. Engine Specification

\begin{tabular}{|c|c|}
\hline Company & Kirloskar \\
\hline Engine Type & 4 Stroke Single Cylinder \\
\hline Power & $5.2 \mathrm{KW}$ \\
\hline Bore & $87.5 \mathrm{~mm}$ \\
\hline Stroke & 110 millimeter \\
\hline Cooling & Water Cooled \\
\hline Speed & 1500 rev \\
\hline Compression Ratio & $17.5: 1$ \\
\hline Fuel Injection & Mechanical Injection with injection timing 230 BTDC, \\
& 210bar injection pressure \\
\hline
\end{tabular}

Fuel Injection Mechanical Injection with injection temporal arrangement 230 BTDC, 210bar injection pressure 


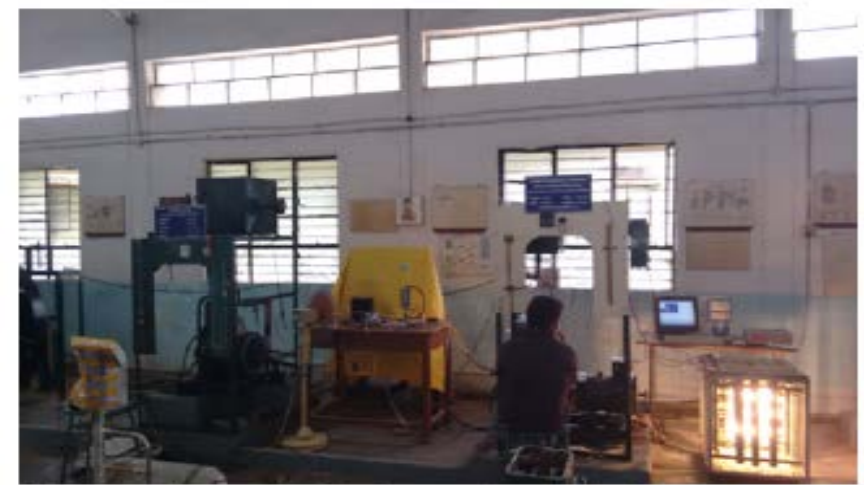

Figure 3. processed, Electrical loading single cylinder four stroke $\mathrm{Cl}$ engine reborn to twin fuel mode with CNG used as a fuel

Figure 3 shows a schematic format of 4 stroke single cylinder ICE on duel fuel mode and figure three demonstrates real image of ICE on double fuel mode. Engine Specification appeared in Table a pair of. The searching examination is to be directed on a four stroke flag cylinder, by dynamic the pressure proportion ICE with CNG as fuel and Diesel, Biodiesel as a pilot fuel. The engine performance and outflow qualities square measure to be assessed by running the engine at totally different the injection temporal arrangement and unsteady burdens.

\section{Results and Discussions}

The results obtained by activity experiments beneath pure diesel mode and twin fuel mode and results square measure shown in figures.

\section{A. Variable the Injection temporal order}

Changing the injection temporal order by variable the amount of shims, thickness of single wedge is zero.124 mm. Engine Performance and emission characteristics of CI engine studies by variable the injection timings.

\section{1) Engine Performance}

Variation of performance parameters at completely different values of injection timings 230 , 260 and a hundred ninety bTDC with a brake power of zero.588 kW, $1.176 \mathrm{~kW}, 1.765 \mathrm{~kW}$, $2.353 \mathrm{~kW}, 2.941 \mathrm{~kW}, 3.5294 \mathrm{~kW}$ and four.118 kW.

Brake Thermal Efficiency: Engine operative condition: Pressure at $210 \mathrm{bar}$, speed 1500rpm and ranging the injection temporal order twenty three zero bTDC, 260 bTDC and a hundred ninety bTDC

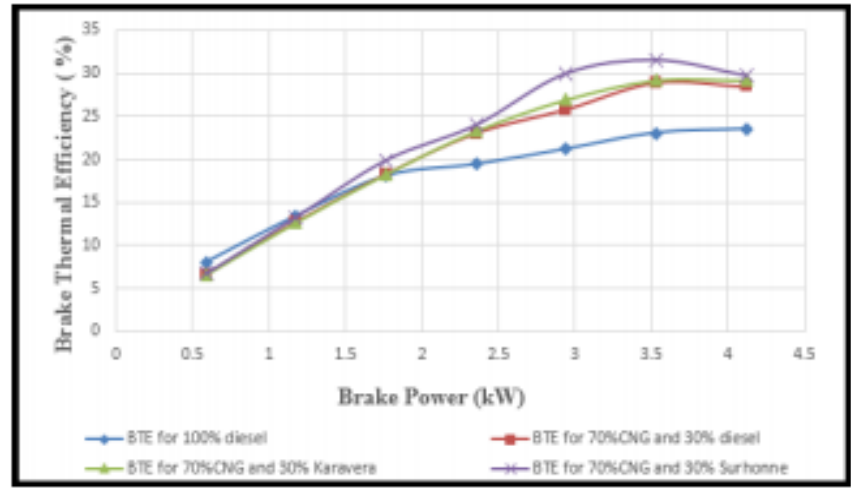

(A) 


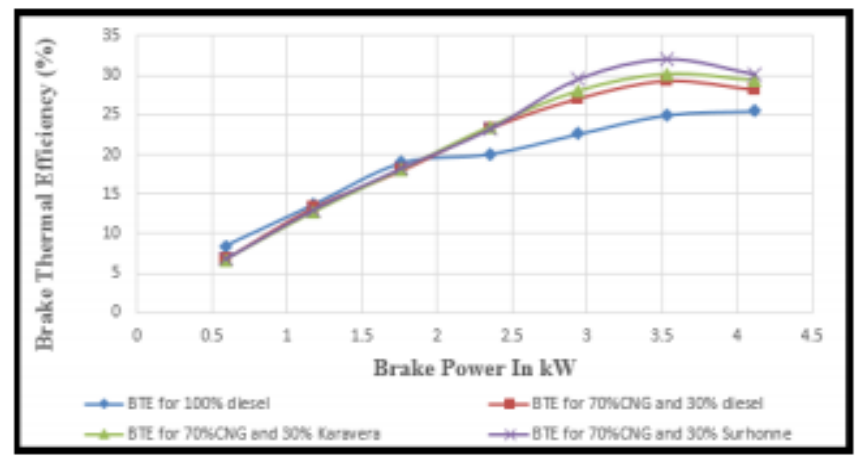

(B)

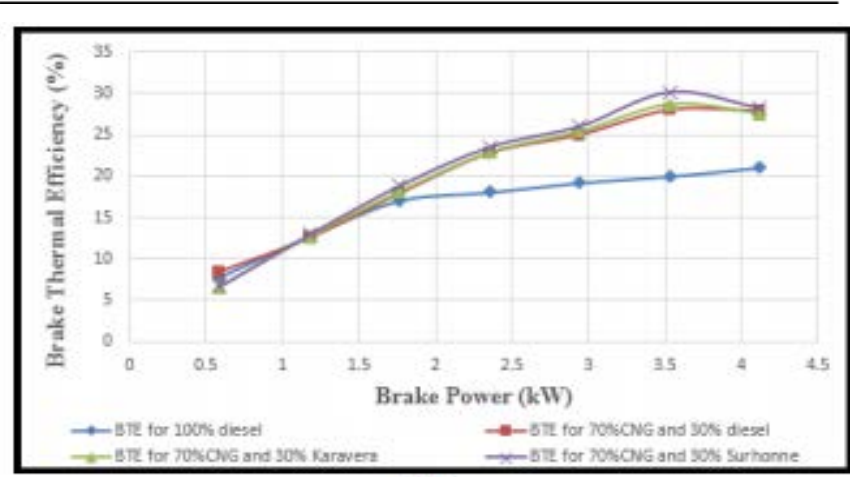

(C)

Figure 4. Comparison of Variation of BTE with BP at injection temporal arrangement 230, 260 and a 190 bTDC at Fig A, B, C.

Variety of BTE with brake management at numerous injection temporal arrangement of 230, 260 and a hundred ninety for the fuel CNG, Surahonne biodiesel, Karavera biodiesel and Diesel for numerous extents area unit appeared within the Figure four A, B, C on an individual basis. From the pattern of brake heat potency with totally different injection temporal arrangement for numerous fuel mixes area unit seen as BTE increments with increment in BP up to half stack condition however at full load condition BTE decreasing with increasing BP as appeared in figure four. the best brake heat potency got thirty first for the fuel seventieth CNG associate degreed half-hour Surahonne at an injection weight of 210 bar at injection temporal arrangement 260. Engine performance of single cylinder CI engine taking an endeavor at double fuel technique of Gases, fluid fuel by dynamical the injection timings the BTE has expanded attributable to increasing begin shelve amount, end ignition of fuel occur. the foremost stripped-down brake heat potency nonheritable for the diesel oil in lightweight of the actual fact that CNG having higher hot incentive than the Diesel.

Specific Fuel Consumption: Engine operative condition: Pressure at 210 bar, speed 1500 rate and ranging the injection timings 230 bTDC, 260 bTDC and a hundred ninety bTDC 


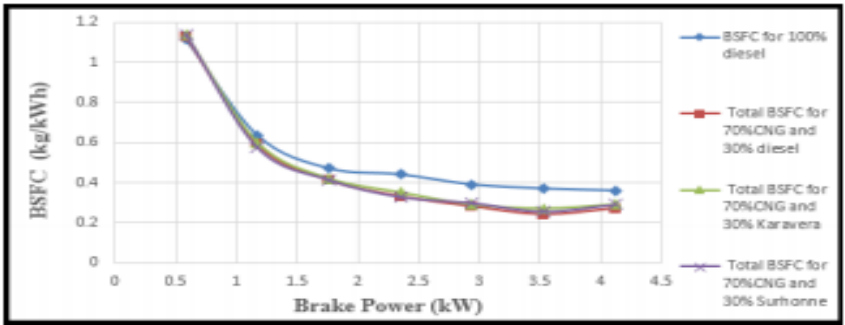

(A)

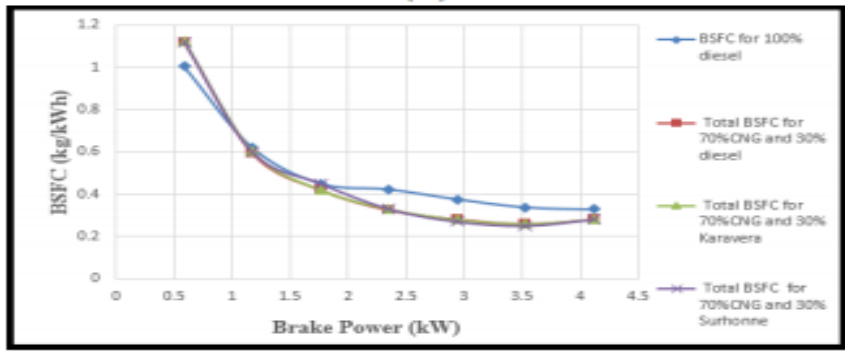

(B)

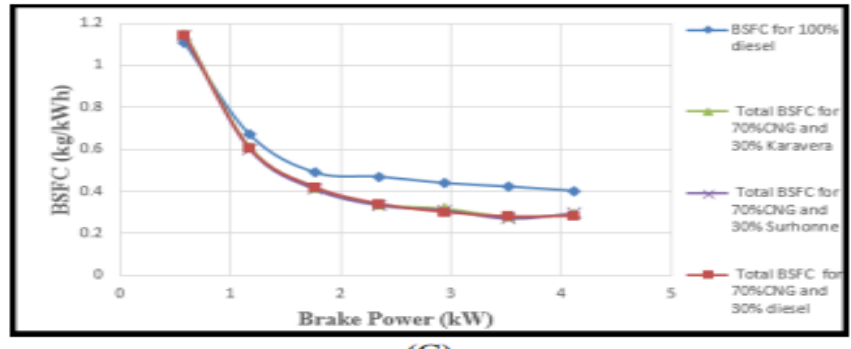

(C)

Figure 5. Comparison of Variation of BSFC with BP at injection timing 230, 260 and 190 bTDC at Fig A, B, C.

Particular Fuel Consumption was computed by fuel utilization separated by the appraised management yield of the engine. type of BSFC with BP for varied injection temporal order 230, 260 and one hundred ninety appeared in Figure five A, B and C one by one. Brake Specific Fuel Consumption for diesel, biodiesel with CNG fuel is determined at varied injection temporal order and hundreds. The engine fuel utilization depends upon velocities, stack and distinctive injection temporal order. It is seen that BSFC is diminished with increasing brake management as a result of high level of transformation of heat vitality into useful work. the foremost extreme BSFC got is one.12 kg/kWh for seventieth CNG with half-hour Surahonne at injection temporal order one hundred ninety. At 230 seventieth CNG and half-hour Diesel is best and at 260 and one hundred ninety seventieth CNG with half-hour Surahonne is best. The abatement in BSFC are processed by the engine stack each area unit conversely corresponding, the speed of increasing brake management is considerably quite that of the expanded fuel utilization as a result of ascend within the burning temperature with stack. The interpretation of heat vitality to mechanical work increments with ascend in ignition temperature which leads modification of BSFC relating to load. what is additional, it's likewise watched that the BSFC has diminished by increasing with preventative injection temporal order. the foremost negligible BSFC is for at injection temporal order one hundred ninety.

\section{2) Emission Characteristics}




\section{a) Carbon monoxide (CO) emission}

Engine operational condition: Pressure at 210 bar, speed 1500 rate and ranging the injection temporal order $230 \mathrm{bTDC}, 260 \mathrm{bTDC}$ and $190 \mathrm{bTDC}$

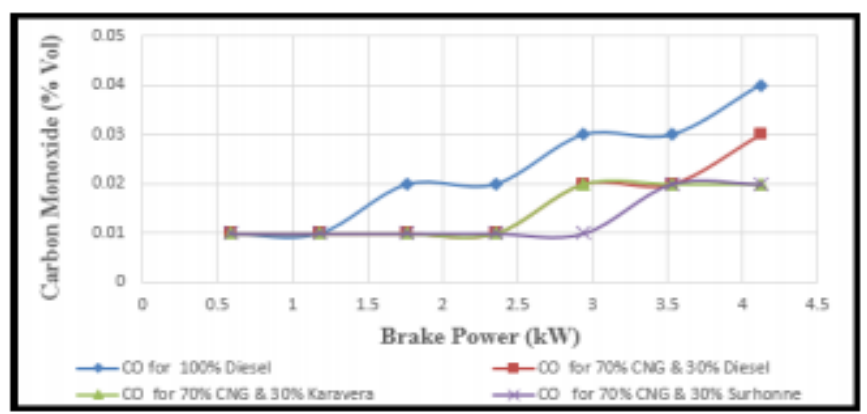

(A)

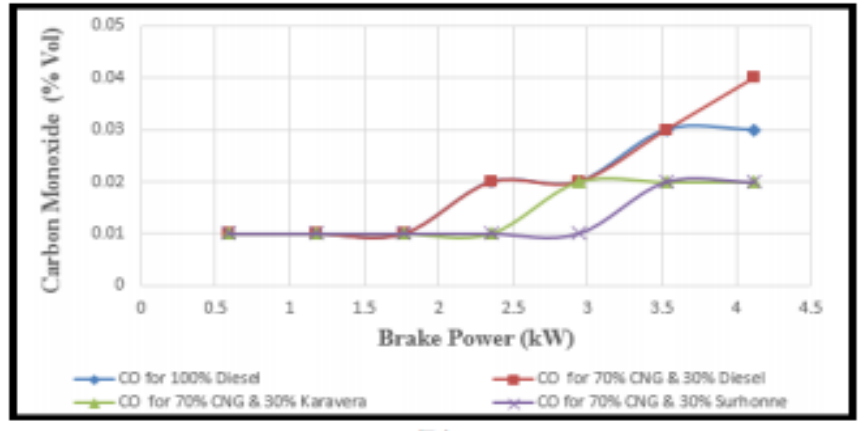

(B)

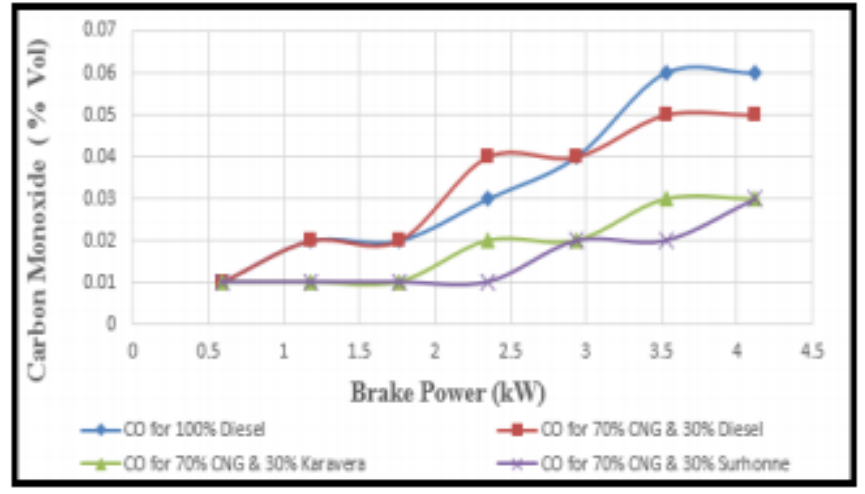

(C)

Figure 6. Comparison of Variation of $\mathrm{CO}$ emission with $\mathrm{BP}$ at injection temporal order 230, 260 and 190 bTDC at Fig A, B, C.

The variety of carbon monoxide with brake control at various injection timing for various fuels as appeared in Figure 6. As we watched that $\mathrm{CO}$ outflow increments with load and discharge diminishes due CNG blends with fuels, in that biodiesel gives less CO emanation than the Diesel fuel. CI engines are working with lean blends the CO discharge ought to be less. So its discharge results to the fragmented burning.

In this means, emanation of CO is hugely dependent on the air to the fuel proportion. made ignition faithfully delivers CO. CO discharge is unsafe thus it have to be compelled to be controlled. $\mathrm{CO}$ is a unprecedented item within the burning of a organic compound fuel. Outflow of $\mathrm{CO}$ is deliberately dependent on the proportion in relevance the ratio extents. made burning 
of fuel produces $\mathrm{CO}$. the smallest amount $\mathrm{CO}$ emanation happened at AN injection temporal order 260 and most extreme CO noninheritable for preventative injection temporal order at 190.

This is because of reality that, when fuel injection timing advance, the start postpone period amid the burning will increment due this entire ignition of fuel happens. Amid impeding injection timing prompts wasteful ignition of fuel in the burning chamber, it causes the CO emanations.

\section{b) Hydrocarbon (HC) emission}

Engine operational condition: Pressure at 210 bar, speed 1500 rev and ranging the injection temporal

arrangement 230 bTDC, 260 bTDC and 190 bTDC

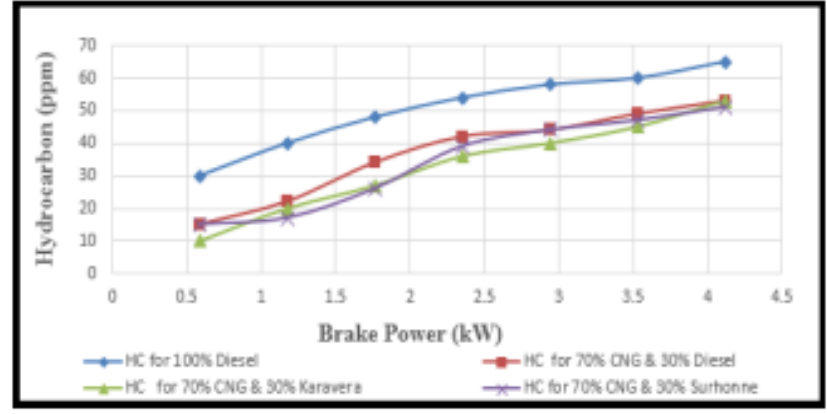

(A)

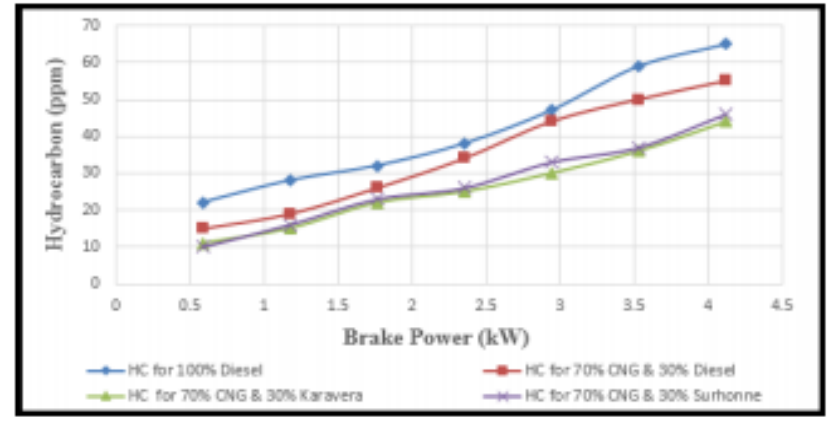

(B)

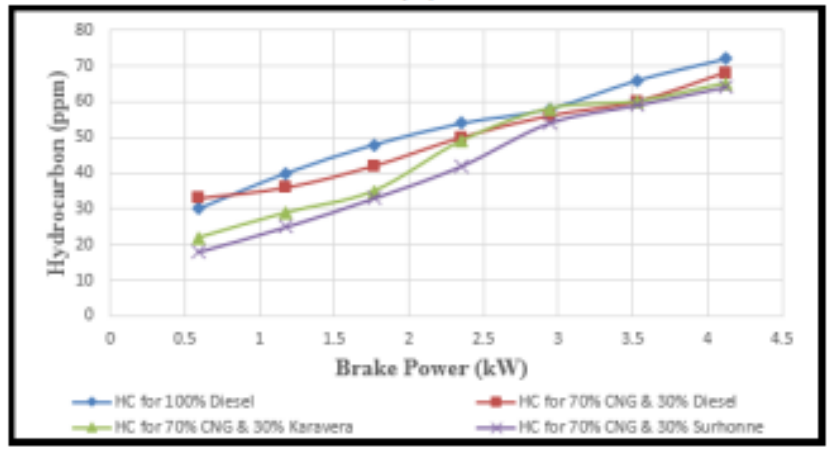

(C)

Figure 7. Comparison of Variation of $\mathrm{HC}$ emission with $\mathrm{BP}$ at injection temporal arrangement 230, 260 and 190 bTDC at Fig A, B, C.

The variety of organic compound with brake management for numerous fuels arrangement and for numerous injection temporal arrangement 230, 260 and a hundred ninety pictured in 
Figure seven A, B and C. separately. organic compound outflow is bring down for biodiesel task at totally different injection timings at injection weight 210 bar. Lower HC outflow at injection temporal arrangement 260 for Karavera biodiesel with CNG fuel as a result of end ignition of fuel at high weight and temperature. the foremost extreme HC emanation happened at obstructive the injection timings. The heedfulness of organic compound of diesel oil is more than biodiesel fuel, because of non-homogeneity of unsaturated fat mix some near spot within the burning chamber have to be compelled to be mix that lean liquidizer ignition fittingly. Some fuel succeed spot overly made with lacking O2, creating it not possible to consumed fuel. In fuel made sight, some live of fuel do not respond as a result of lacking of $\mathrm{O} 2$ and therefore the burning are going to be fragmented. as a result of this higher the HC emanation on account of obstructive the injection temporal arrangement contrasted with dynamic injection temporal arrangement. Surhonne and Karavera Biodiesel as a pilot fuel instead of Diesel half-hour HC outflow reduction at injection temporal arrangement 230 , [*fr1] reduction at injection temporal arrangement 260 and Bastille Day reduction at injection temporal arrangement a hundred ninety.

c) Carbon dioxide (CO2) emission

Engine in operation condition: Pressure at 210 bar, speed 1500 rev and ranging the injection temporal

arrangement 230 bTDC, 260 bTDC and 190 bTDC

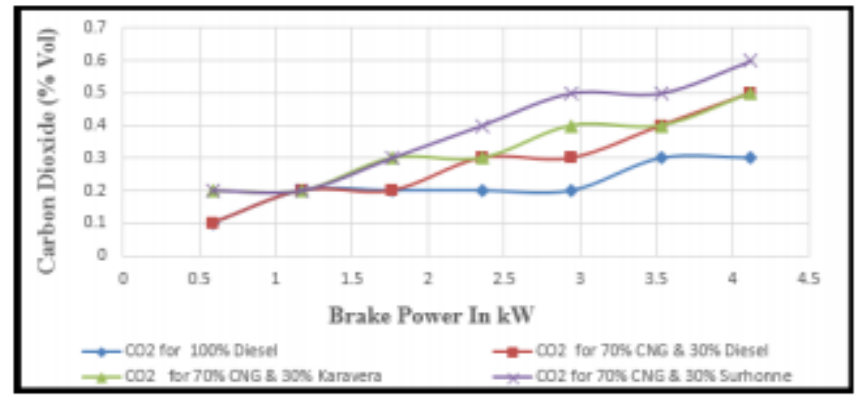

(A)

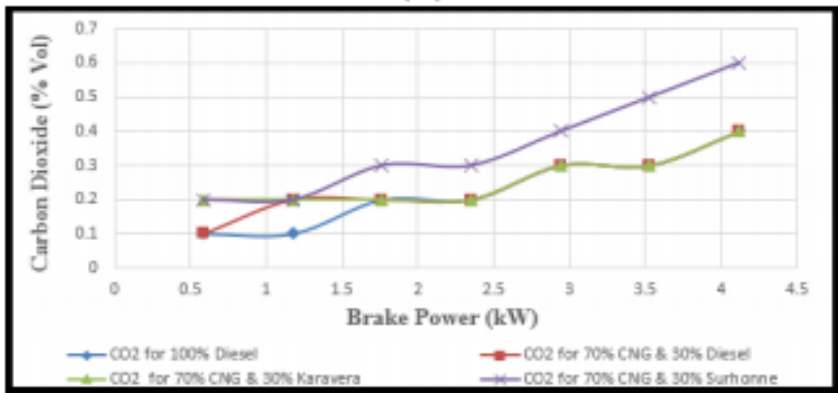

(B)

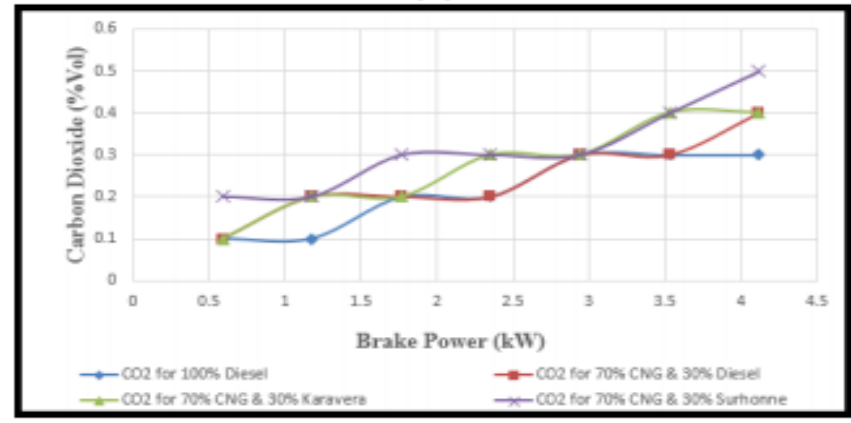

(C) 
Figure 8. Comparison of Variation of greenhouse gas emission with BP at injection temporal arrangement 230, 260 and 190 bTDC at Fig A, B, C.

Carbon dioxide happens naturally in the climate. Preferably, ignition of a HC fuel create CO2 and water. Variety of CO2 with BP at various injection timing 230, 260 and 190 for the fuels are appeared in Figure 8 A, B and C. individually. CO2 outflow fluctuates from $0.10 \%$ to $0.70 \%$ for diesel at various injection timing with injection weight 210 bar. In the event that fuels are totally combusted than gives more $\mathrm{CO} 2$ emanation implies fuel got adequate measure of oxygen to respond with hydrocarbons and the most extreme $\mathrm{CO} 2$ outflow happens at propelling injection timings at 260.

\section{3) Peak Pressure Curves for changing the injection timing}

Peak Pressure are shown for diesel, diesel with CNG, Karavera biodiesel with CNG and Surahonne biodiesel with CNG at various injection timings as shows bellow figures

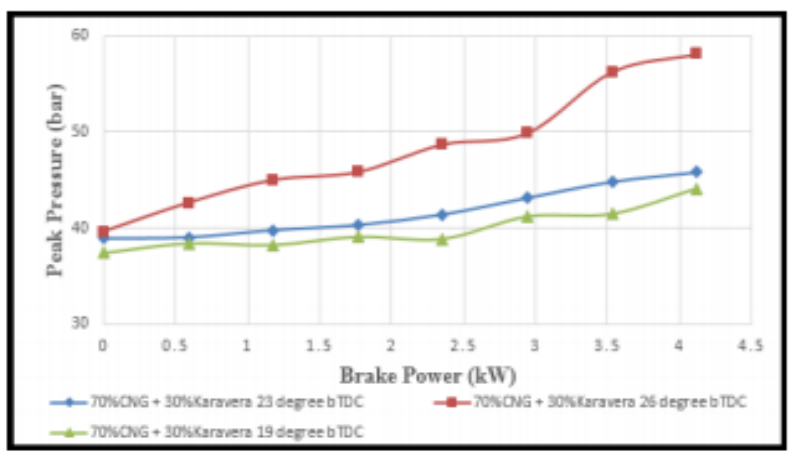

(A)

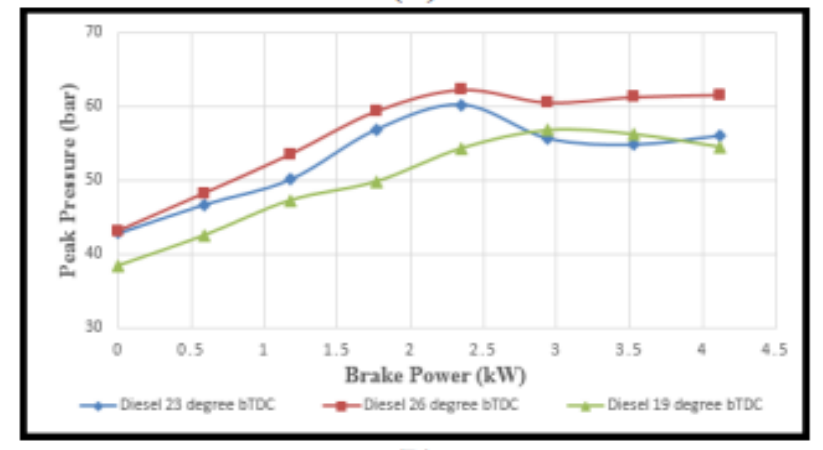

(B)

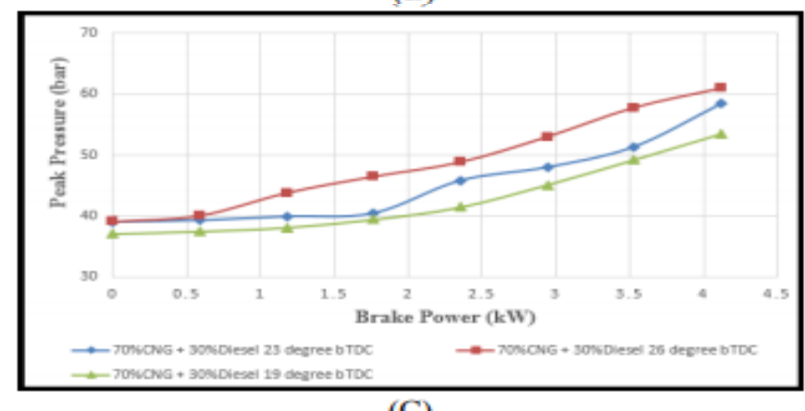

(C) 


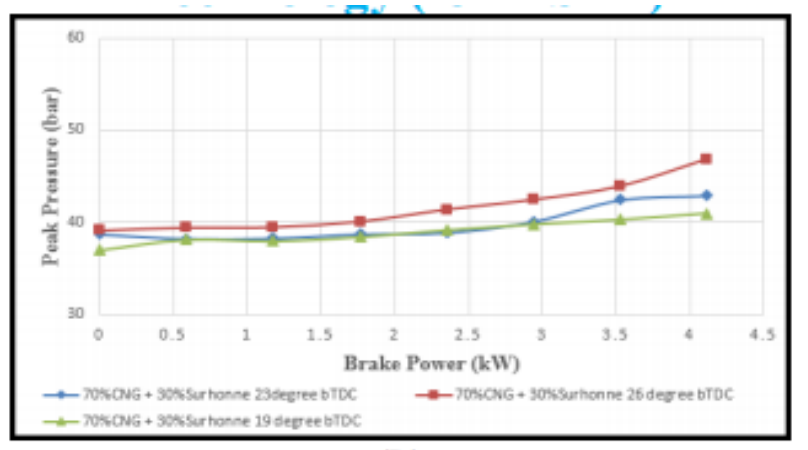

(D)

\section{Figure 9. Variation of Peak Pressure with BP for variable injection temporal arrangement at Figure $A, B, C$ and $D$}

Variety of Peak Pressure with brake control appeared in Figure 9. It is unmistakably observed that pinnacle weight ascend by propelling the injection timing and pinnacle weight reduction because of hindering the pinnacle weight. Most extreme Peak weight ascend for Diesel with CNG fuel. At no heap crest weight rise not as much as the full load because of defer period, weight and temperature. High thick fuel like biodiesel less pinnacle weight ascend because of moderate consuming. Pinnacle weight rise is go between $40-60$ bar, as load builds top weight rises.

\section{Conclusion}

From the results obtained, the fallowing conclusion square measure created. A. Achieved seventieth replacement of fuel over CNG at twin fuel mode. B. twin fuel operation is extremely effective technique to cut back change state hydrocarbons. C. Advancing the injection temporal arrangement increase the Brake Thermal potency. D. Advancing the injection temporal arrangement reduction of $\mathrm{CO}$ and $\mathrm{HC}$ emission. E. the most BTE obtained thirty first at injection temporal arrangement 260 with fuel seventieth CNG and half-hour Surahonne biodiesel. F. Best result's obtained for engine performance and emission at injection temporal arrangement 260 with fuel seventieth CNG and half-hour Surahonne biodiesel, CO and HC emission reduction takes place up to $50 \%$

\section{References}

[1] Chindo Istifanus Yarkasuwa, Danbature Wilson, and Emmanuel Michael, "Production of Biodiesel from Yellow Oleander (Thevetia peruvian) Oil and its Biodegradability”. Journal of the Korean Chemical Society, Vol. 57, No. 3. pp.377-381, (2013). DOI: 10.5012/jkcs.2013.57.3.377

[2] "Investigation on the flow Behavior of a Venturi type gas mixer designed for dual fuel diesel engines". International Journal of Emerging Technology and Advanced Engineering Volume 3, Special Issue 3: ICERTSD 2013, Feb (2013), pp.202-209 An ISO 9001:2008 certified Int. Journal, ISSN 2250-2459.

[3] Mahesh M.Patil and Dr.R.R.Arakerimath “Analysis of Exhaust Emission, and Performance Characteristics of Single Cylinder CI Engine Fuelled With Palm Oil and CNG”. International Journal of Innovative Research in Science, Engineering and Technology Vol. 4, Issue 1, January (2015) ISSN (Online): 2319-8753.

[4] M C Navindgi1, Dr. Maheswar Dutta and Dr. B. Sudheer Prem Kumar "Experimental Investigation of Performance and Emission Characteristics of CI Engine Using CNG and Neem Oil Blend”. International Journal of Advanced Trends in Computer Science and Engineering, Vol.2, No.6, pp.01-04 (2013) ISSN: 22783091. 
[5] M.Noor, K.Kadirgama, R.Devarajan, M.R.M.Rejab, N.M.Zuki N.M. and T.F.Yusaf "Development of a High Pressure Compressed Natural Gas Mixer for A 1.5 Liter CNG-Diesel Dual Engine”. National Conference on Design and Concurrent Engineering, Faculty of Mechanical Engineering, University Malaysia Pahang, 26300 Kuantan, Pahang, Malaysia. (2008)

[6] Mr. A. Raj Kumar, Mr. M.Chakrapani, Dr. G. Janardhana Raju and Dr. Hemachandra Reddy "Evaluation of C.I Engine Performance and Emission Characteristics Fueled with CNG and Ethanol Blends as Alternative Fuel”. International Journal for Research in Applied Science and Engineering Technology (IJRASET), vol. 2 issue viii, august (2014) ISSN: 2321-9653.DOI: 10.1016/S0735-1097(14)60619-7 